\title{
An ideal laser for hair reduction in ethnic skin
}

\author{
Neerja Puri* \\ Consultant Dermatologist, Punjab Health Systems Corporation, India
}

\begin{abstract}
There are various types of lasers available for hair reduction, but the choice of an ideal laser for ethnic skin has its own limitations. The choice of the right laser for the right skin type is very important. Before starting with the laser therapy, it is important to assess the skin type, the fluence, the pulse duration and the type of laser to be used.
\end{abstract}

\section{Introduction}

Hirsutism refers to the growth of coarse terminal hair in females that follows a male like pattern, most commonly in the upper lip area, beard area, abdomen, or chest [1-4]. Laser systems that are commonly used for the treatment of hirsutism include the ruby laser $(694 \mathrm{~nm})$, the diode laser $(800 \mathrm{~nm})$, the alexandrite laser $(755 \mathrm{~nm})$ and the Nd:YAG laser (1084 nm) and Intense Pulse Light (IPL) laser. The diode laser and alexandrite laser are considered effective in treatment of hirsutism in dark skinned patients $[5,6]$. The response of hairs to these laser systems is variable and not complete. Because melanin in the epidermis and in the hair follicle have nearly identical absorption spectra, laser hair removal poses a real risk of epidermal injury, especially in darker skin types $[7,8]$. The long pulsed diode $(810 \mathrm{~nm})$ and $\mathrm{Nd}$ :Yag $(1064 \mathrm{~nm})$ have combined longer wavelengths, extended pulse durations, and active epidermal cooling to provide the greatest efficacy with the lowest side effect profile in treating skin phototypes IV-VI. $[9,10]$. When the longpulsed diode to treat skin phototypes IV-VI is used, pulse durations of 100 milliseconds or longer improve the ability to treat darker skin more safely. In terms of treating very dark skin, phototype VI very long pulse durations ( $400 \mathrm{~ms}$ ) have been reported and aggressive adjunctive skin cooling are required. Because of its longer wavelength, the Nd:Yag has been shown to be the safest laser to treat darker skin types $[11,12]$. Its longer wavelength minimizes epidermal melanin absorption and maximizes wavelength penetration to the dermal hair follicular unit.

During laser hair removal, a laser beam passes through the skin to an individual hair follicle. The intense heat of the laser damages the hair follicle, resulting in reduction of the number of hairs and the quality of hair $[13,14]$. Hair will be less noticeable, finer, and possibly lighter. The degree of hair reduction depends on the number of treatments. Laser hair removal focuses on the endogenous chromophore melanin, which is mainly found in the hair shaft, with a small amount present in the upper third of the follicular epithelium. When an appropriate energy source (such as a laser) is directed at the skin, light is primarily absorbed in the hair shaft melanin. Hair removal lasers generally work on the principle of selective photothermolysis, based on selective absorption of laser energy by the components of the hair follicle. The target chromophore is melanin contained by the follicle, which has a broad absorption spectrum. Wavelengths between approximately 700 and 1000 nanometers ( $\mathrm{nm}$ ) are selectively absorbed by melanin; the competing chromophores (oxyhemoglobin and water) absorb less energy at these wavelengths.

\section{Discussion}

Permanent hair reduction means that the majority of undesirable hairs will be destroyed and not re-grow. Potentially, it may leave a smaller percentage of finer or light vellus hair [15]. Pigmented hairs are permanently destroyed and the finer less pigmented hairs normally reduce and achieve long term removal. We should use the term long term hair reduction rather than permanent hair removal as the laser technology is hardly two decades old. Melanin content and pulse duration are two important criteria for achieving effective hair reduction with lasers. Effective hair reduction is possible if the melanin within the hair shaft, hair follicle epithelium, and the heavily pigmented matrix, and also the stem cells in the area of the bulge, are targeted [16,17]. Only lasers with wavelengths ranging from 630 to $1100 \mathrm{~nm}$ can irradiate the entire length of anagen hair extenging 2-5 $\mathrm{mm}$ into the dermis. In addition, pulse duration serves as an important parameter for effective photoepilation which should be shorter than or equal to the TRT of the hair shaft. Both melanin content and TRT increase as the diameter of the hair shaft increases. A terminal hair has an average diameter of $60-80 \mu \mathrm{m}$. Vellus hairs are $<40 \mu \mathrm{m}$ in diameter and contain little melanin, while the intermediate hair would fall somewhere in between [18]. Therefore, for intermediate or a finer hair, a shorter TRT would be required which is not fully safe in darker skin, as it might be insufficient for an optimum cooling of the epidermis. In such a scenario, it is quite understandable that it is far easier and safer to remove a terminal hair than an intermediate hair, and even less so, a vellus hair. This is one of the reasons that most laser hair reduction studies have been performed on dark terminal hair only. The response to laser hair reduction varies depending on the type of hair. Dark, coarse terminal hair responds better than fine, low-density intermediate hair.

Different types of lasers used for hair reduction $[18,19]$ are: Ruby laser $694 \mathrm{~nm}$; Alexandrite laser--755 nm; Diode laser--800 nm; Neodymium-yttrium-aluminium-garnet (Nd:YAG) laser--1064 nm;

Correspondence to: Dr. Neerja Puri, House No: 626, Phase II, Urban Estate, Dugri Road, Ludhiana, Punjab, India, Tel: 0091-98146-16427; E-mail: neerjaashu@rediffmail.com

Key words: hair reduction, Lasers, diode, Nd YAG, intense pulsed light, hair follicle, melanin, chromophore

Received: December 27, 2014; Accepted: January 16, 2015; Published: January 19,2015 
Intense Pulsed Light System (IPL) without heat--550-1200 nm. We will now discuss the pros and cons of each laser one by one.

The Diode Laser (Figure 1 and 1a) is most effective for darker skin types and is less effective on dark coarse hair. It covers large areas and has fast repetition rates, allowing brisk treatment of large body areas [20,21]. Diode lasers are solid-state laser devices that have been very well received over the past several years because of their reliability and their ability to penetrate even deeper into the skin, thus, allowing even darker and perhaps tanned individuals to be successfully treated for epilation of unwanted hair. In a study, a comparative study was done of different type of lasers and it was seen that best results were obtained with diode laser followed by alexandrite laser [22]. These devices also use sophisticated cooling apparatus, thus, assuring increased safety for our patients. The most popular of the diode laser systems for hair removal is the LightSheer produced by Lumenis, Santa Clara, Calif. This is an $810 \mathrm{~nm}$ diode laser with pulse widths that vary from 5 up to a newly introduced model, up to 400 milliseconds, allowing darker skin types to be easily treated. The spot size is $12 \times 12 \mathrm{~mm}$, and it uses a fast repetition rate of $2 \mathrm{~Hz}$, as well as fluences between 10 and 60 $\mathrm{J} / \mathrm{cm}^{2}$. It has its own contact cooling device known as ChillTip in its stand-alone version and Sapphire Cooled Tip in the Lumenis One model. The better results obtained with the diode laser may had been enhanced partly by the cooling effect of the integrated sapphire and the pressure exerted by it on the skin. Sapphire is ideal, as it has excellent thermal characteristics and operates as a heat sink removing heat from the epidermis. This enables the target structures to be heated more efficiently, so that less fluences are required, resulting in less thermal load on the epidermis [23-25].

The long pulse Neodymium-yttrium aluminum-garnet laser (Nd:Yag laser) can be safely used in all skin types, including tanned patients. Large coverage areas and fast repetition rates allow large areas to be treated quickly. It causes more discomfort during treatment. It

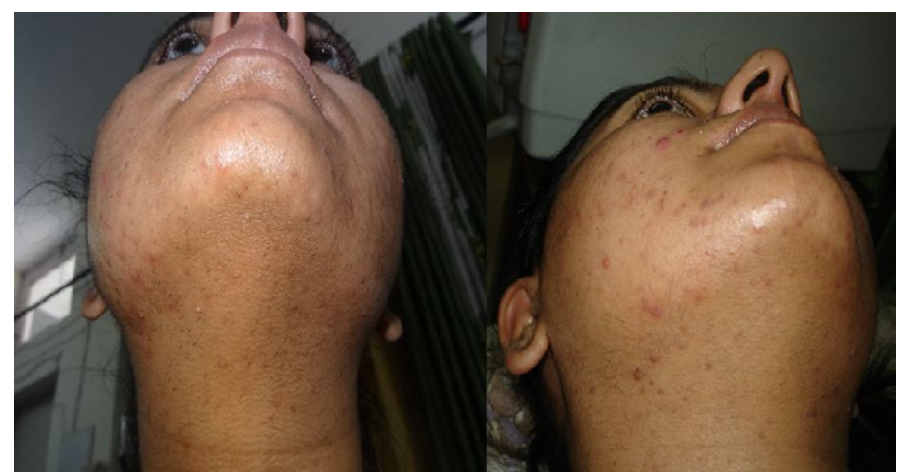

Figure 1. Treatment by the Diode Laser.
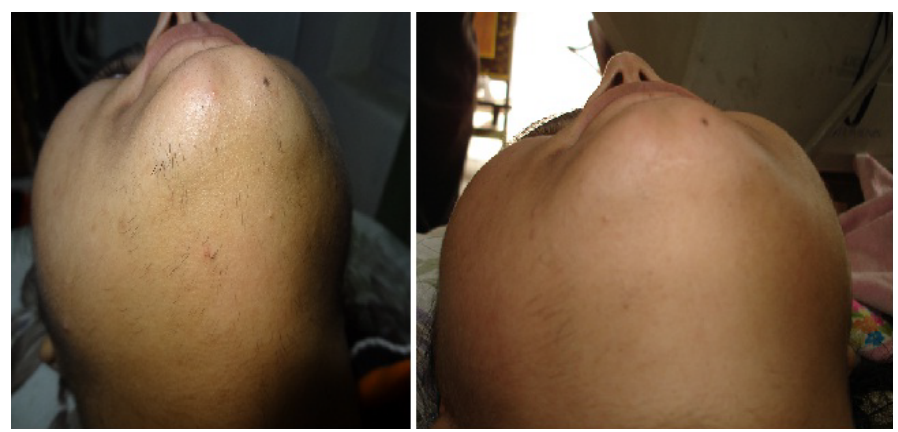

Figure 2. Treatment by The long pulsed Nd:YAG.
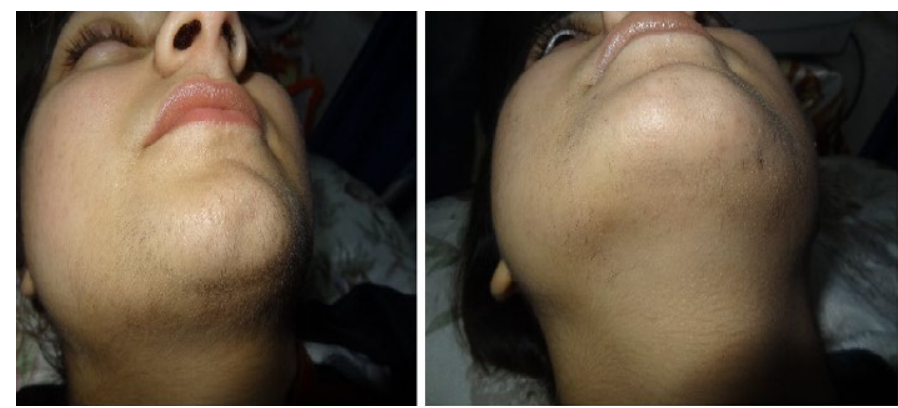

Figure 3. Treatment by IPL devices.

is also less effective for fine and light hair than other lasers [26,27]. The long pulsed Nd:YAG (Figures 2 and 2a) is the safest laser for hair removal in darker skin types. Two factors contribute to the safety of the long pulsed Nd:YAG in darker skin types. First, the wavelength of the Nd:YAG $(1064 \mathrm{~nm})$ is at the end of the absorption spectrum of melanin. This wavelength is sufficient to achieve significant thermal injury in dark coarse hairs while sparing epidermal pigment. Secondly, the adjustable pulse width of long pulsed Nd:YAG lasers allows the laser energy to be delivered over a longer period of time allowing for the heat to dissipate and sufficient epidermal cooling to occur $[28,29]$ long-pulsed Nd:YAGlaser, $1064 \mathrm{~nm}$ wavelength, has emerged as an effective hair removal system with lesserside effects. The long-pulsed $\mathrm{Nd}$ :YAG lasers are receiving the most attention at this time, and numerous systems are available using this long wavelength of light. At this wavelength of light, melanin absorption is reduced, which require higher fluences (power) to damage the hair effectively. Epidermal cooling devices incorporated into these devices ensure a reduction in the potential for epidermal injury and allow them to be successfully used in patients with dark skin (up to skin type VI). The $1064 \mathrm{~nm}$ wavelength Nd YAG laser is the safest wavelength for the treatment of olive to dark skin types. It is this lesser attraction to melanin that gives it a larger margin of safety when performing laser hair removal on darker skin types as it bypasses the surface colour of the skin.

Intense Pulsed Light Devices are not lasers, but are "laser equivalents" in the sense that they use the same concept of selective photothermolysis to accomplish hair removal. IPL devices (Figures 3 and 3a) are more difficult to use than lasers and require a very skilled and experiences technician to operate [30,31]. The IPL systems, a nonlaser light source, have evolved steadily over this period and, today, remain one of the most common and dependable epilation modalities available. IPL is far less effective than Laser Hair Removal. The energy is produced by a lamp, a little like a light bulb, and produces a variety of light waves, meaning that it is more diffuse and less powerful. It is usually limited to use on fairer skin types [32,33]. IPL devices also offer sophisticated, computer driven precision and tremendous versatility, the key benefit of IPL system is its cost-effectiveness. Larger treatment areas can be easily treated because of larger spot size. By pulsating, this IPL technology breaks up the light energy to create a skin cooling effect so that the skin's surface is spared from the higher thermal temperatures [33,34]. Laser intergrated cooling systems are also used to cool the epidermis.

Long Pulsed Alexandrite $755 \mathrm{~nm}$ laser is also used worldwide. It is an effective laser with more depth of penetration in comparison to IPL and Nd YAG lasers $[35,36]$. It exerts effect on the hair follicle by applying the principle of selective photothermolysis.

In terms of efficacy, the shorter wavelength (diode) laser is 
generally regarded as more effective because of 'melanin's higher absorption value which decreases with increasing wavelength [37]. However, the longer wavelength Nd: YAG laser is considered ideal for treating patients with darker skin, due to reduced scatter and deeper penetration of the laser light. Also, shorter pulse durations can be more safely used with the Nd: YAG laser than with the diode [38,39]. This is an additional advantage when dealing with finer hair with shorter Thermal Relaxation Time (TRT).

\section{Conclusions}

To conclude, for Indian skin, diode laser is the ideal laser affecting coarse thick hairs, whereas IPL laser is not suitable for dark skinned Indians as it targeted only fine hairs. Choosing the right machine is very important especially in ethnic skin. One should select a machine with right spot size, fluence, pulse width and frequency. Also, selecting the right settings depending on the skin type, color, hair color and hair thickness is very important. Also, one should have good cooling devices. For refractory cases of hirsutism, proper work up of the patients is essential to rule out any cases of polycystic ovarian disease. Last but not the least, is timely servicing and maintainance of the machines is also important.

\section{References}

1. Azziz R, Waggoner WT, Ochoa T, Knochenhauer ES, Boots LR (1998) Idiopathic hirsutism: an uncommon cause of hirsutism in Alabama. Fertil Steril 70: 274-278. [Crossref]

2. Dawber RP (2005) Guidance for the management of hirsutism. Curr Med Res Opin 21: 1227-1234. [Crossref]

3. Messenger AG (1993) The control of hair growth: an overview. J Invest Dermatol 101: 4S-9S. [Crossref]

4. Rosenfield RL (2005) Clinical practice. Hirsutism. N Engl J Med 353: 2578-2588. [Crossref]

5. Battle EF Jr, Hobbs LM (2004) Laser-assisted hair removal for darker skin types. Dermatol Ther 17: 177-183. [Crossref]

6. Kono T, Nozaki M. Diode Laser-Assisted Hair Removal in Asians: A Study of 101 Japanese Patients. Coherent, 2000.

7. Hamilton MM, Dayan SH, Carniol PJ (2001) Laser hair removal update. Facial Plast Surg 17: 219-222. [Crossref]

8. Dierickx C, Alora MB, Dover JS (1999) A clinical overview of hair removal using lasers and light sources. Dermatol Clin 17: 357-366, ix. [Crossref]

9. Lou WW, Quintana AT, Geronemus RG, Grossman MC (2000) Prospective study of hair reduction by diode laser $(800 \mathrm{~nm})$ with long-term follow-up. Dermatol Surg 26: 428-432. [Crossref]

10. Lask G, Eckhouse S, Slatkine M, Waldman A, Kreindel M, et al. (1999) The role of laser and intense light sources in photo-epilation: a comparative evaluation. J Cutan Laser Ther 1: 3-13. [Crossref]

11. Bencini PL, Luci A, Galimberti M, Ferranti G (1999) Long-term epilation with longpulsed neodimium:YAG laser. Dermatol Surg 25: 175-178. [Crossref]

12. Lévy JL, Trelles MA, de Ramecourt A (2001) Epilation with a long-pulse $1064 \mathrm{~nm}$ Nd:YAG laser in facial hirsutism. J Cosmet Laser Ther 3: 175-179. [Crossref]

13. Wheeland RG (1997) Laser-assisted hair removal. Dermatol Clin 15: 469-477. [Crossref]

14. Ross EV, Ladin Z, Kreindel M, Dierickx C (1999) Theoretical considerations in laser hair removal. Dermatol Clin 17: 333-355, viii. [Crossref]

15. Tanzi EL, Lupton JR, Alster TS (2003) Lasers in dermatology: four decades of progress. J Am Acad Dermatol 49: 1-31. [Crossref]

16. Klavuhn KG, Green D (2002) Importance of cutaneous cooling during photothermal epilation: theoretical and practical considerations. Lasers Surg Med 31: 97-105. [Crossref]

17. Liew SH (1999) Unwanted body hair and its removal: a review. Dermatol Surg 25: 431-439. [Crossref]
18. Hamilton MM, Dayan SH, Carniol PJ (2001) Laser hair removal update. Facial Plast Surg 17: 219-222. [Crossref]

19. Bouzari N, Tabatabai H, Abbasi Z, Firooz A, Dowlati Y (2004) Laser hair removal: comparison of long-pulsed Nd:YAG, long-pulsed alexandrite, and long-pulsed diode lasers. Dermatol Surg 30: 498-502. [Crossref]

20. Chan HH, Ying SY, Ho WS, Wong DS, Lam LK (2001) An in vivo study comparing the efficacy and complications of diode laser and long-pulsed Nd:YAG laser in hair removal in Chinese patients. Dermatol Surg 27: 950-954. [Crossref]

21. Lou WW, Quintana AT, Geronemus RG, Grossman MC (2000) Prospective study of hair reduction by diode laser $(800 \mathrm{~nm})$ with long-term follow-up. Dermatol Surg 26: 428-432. [Crossref]

22. Sadick NS, Prieto VG (2003) The use of a new diode laser for hair removal. Dermatol Surg 29: 30-33. [Crossref]

23. Narurkar V (2003) Evaluation of a New 400 ms Extended Pulse LightSheer System for Safe and Effective Hair Removal. Lumenis.

24. Galadari I (2003) Comparative evaluation of different hair removal lasers in skin types IV, V, and VI. Int J Dermatol 42: 68-70. [Crossref]

25. Campos VB (2002) Safe and Effective Long-term Hair Reduction in Tanned Patients Using an $800 \mathrm{~nm}$ Diode Laser. Lumenis.

26. Alster TS, Bryan H, Williams CM (2001) Long-pulsed Nd:YAG laser-assisted hair removal in pigmented skin: a clinical and histological evaluation. Arch Dermatol 137 885-889. [Crossref]

27. Littler CM (1999) Hair removal using an Nd:YAG laser system. Dermatol Clin 17: 401-430, x. [Crossref]

28. Goldberg DJ, Silapunt S (2001) Histologic evaluation of a millisecond Nd:YAG laser for hair removal. Lasers Surg Med 28: 159-161. [Crossref]

29. Lorenz S, Brunnberg S, Landthaler M, Hohenleutner U (2002) Hair removal with the long pulsed Nd:YAG laser: a prospective study with one year follow-up. Lasers Surg Med 30: 127-134. [Crossref]

30. Tanzi EL, Alster TS (2004) Long-pulsed 1064-nm Nd:YAG laser-assisted hair remova in all skin types. Dermatol Surg 30: 13-17. [Crossref]

31. Gold MH, Bell MW, Foster TD, Street S (1999) One-year follow-up using an intense pulsed light source for long-term hair removal. J Cutan Laser Ther 1: 167-171. [Crossref]

32. Omi T, Clement RM (2006) The use of a constant spectrum, uniform temporal profile intense pulsed light source for long-term hair removal in Asian skin. J Cosmet Laser Ther 8: 138-145. [Crossref]

33. El Bedewi AF (2004) Hair removal with intense pulsed light. Lasers Med Sci 19: 4851. [Crossref]

34. Weiss RA, Weiss MA, Marwaha S, Harrington AC (1999) Hair removal with a noncoherent filtered flashlamp intense pulsed light source. Lasers Surg Med 24: 128-132. [Crossref]

35. Gold MH, Foster TD, Street ST (2002) Long-term hair removal utilizing the intense pulsed light source: a two year follow-up study. Intl J Cosmet Surg \& Aesthet Derm 4: $15-26$.

36. Schroeter CA, Raulin C, Thürlimann W, Reineke T, De Potter C, et al. (1999) Hair removal in 40 hirsute women with an intense laser-like light source. Eur J Dermato 9: 374-379. [Crossref]

37. Handrick C, Alster TS (2001) Comparison of long-pulsed diode and long-pulsed alexandrite lasers for hair removal: a long-term clinical and histologic study. Dermatol Surg 27: 622-626. [Crossref]

38. Eremia S, Li C, Newman N (2001) Laser hair removal with alexandrite versus diode laser using four treatment sessions: 1-year results. Dermatol Surg 27: 925-929. [Crossref]

39. Saleh N, Badr Y, Shokeir H, Soliman M, Salah M, et al. (2005) Comparative study between ruby, alexandrite and diode lasers in hirsutism. Egyptian Dermatology online journal 1: 1-1.

Copyright: (C2015 Puri N. This is an open-access article distributed under the terms of the Creative Commons Attribution License, which permits unrestricted use, distribution, and reproduction in any medium, provided the original author and source are credited. 